\title{
Influence of the Power of Various Types of Induction Furnaces on the Shape of the Metal Bath Surface
}

\author{
Albert Smalcerz ${ }^{1 *}$, Bartosz Węcki², Leszek Blacha ${ }^{3}$ \\ 1 Faculty of Materials Science, Department of Industrial Informatics, Silesian University of Technology, \\ Krasinskiego 8, 40-019 Katowice, Poland \\ 2 Department of Testing and Certification "ZETOM", Ks. Herberta Bednorza 17, 40-384 Katowice, Poland \\ 3 Faculty of Materials Science, Department of Metallurgy and Recycling, Silesian University of Technology, \\ Krasinskiego 8, 40-019 Katowice, Poland \\ * Corresponding author's email: albert.smalcerz@polsl.pl
}

\begin{abstract}
The work shows the results of examinations conducted to ascertain the influence of the working power of a vacuum induction crucible furnace (ICF) and a furnace with a cold crucible (CCF), on the surface area of liquid Al-Zn alloy molten within these devices. It was determined that the increase of the value of this parameter causes the increase of the liquid alloys surface area. In the case of smelting alloy inside a crucible furnace the increase of power from 8 to $22 \mathrm{~kW}$ causes the increase of liquid alloy surface from 88 to $155 \mathrm{~cm}^{2}$. For a furnace with a cold crucible, the power increase from 70 to $130 \mathrm{~kW}$ causes the increase of the alloy surface from 280 to $330.3 \mathrm{~cm}^{2}$. For all power values a larger increase in surface area was observed in crucible furnaces (around two times). In cases of cold crucible furnaces, this increase was around $20 \%$. Additionally, based on the examination results the way in which the surface area of liquid alloy can intensify the undesirable process of zinc fuming away, was discussed. It has been demonstrated that the process of zinc elimination from the examined alloy is more intensive while using a cold crucible induction furnace.
\end{abstract}

Keywords: Al-Zn alloys, induction vacuum furnace, cold crucible furnace, metal bath surface.

\section{INTRODUCTION}

Crucible based vacuum induction furnaces (ICF), such as induction furnaces with cold crucibles (CCF) are melting machines used in contemporary refining or metal smelting processes. Inside crucible furnaces, the source of the electromagnetic field is a cylindrical coil made out of a copper conductor. Inside the coil is a non-conductive crucible (ceramic) or a conductive one (graphite or steel). In the case of the first heating of the insert is direct, in the case of the latter it is indirect, in which eddy currents are induced inside the crucible, and the heat is conducted through it into the insert. The way the electromagnetic field is shaped outside of the furnace is often shaped through magnetic cores, or through magnetic field concentrators. The magnetic stream is generated through the electricity between the insert and coil. The outer cores or concentrators create a magnetic circuit, closing the stream inside the furnace chamber, limiting the heating of the furnace outer casing. Figure 1 shows, how the magnetic core is longer than the induction coil. This limits the expansion of the field outside of the furnace. It is an important element in the construction of such machines.

Inside crucible induction furnaces the generation of heat happens primarily inside the insert itself. The transfer of energy between the coil and insert usually happens without them touching. The source of the energy created inside the insert of an induction furnace 


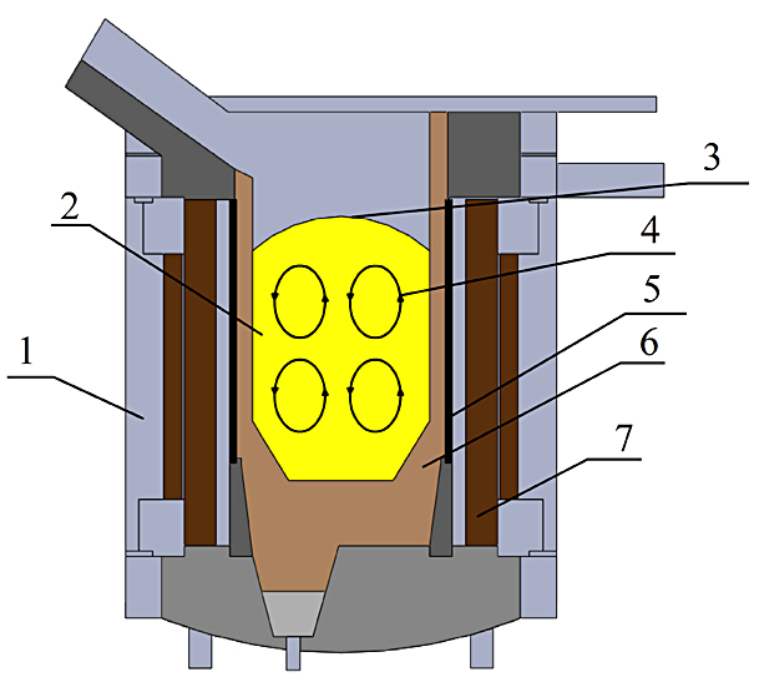

Fig. 1. Scheme of the induction crucible furnace: 1 - steel construction; 2 - liquid metal; 3 - meniscus; 4 - mixing of metal; 5 - inductor; 6 - crucible; 7 - ferromagnetic core [1]

is alternating electrical current flowing through the coil. The purpose of the induction coil is the forming and shaping of an electromagnetic field (especially the magnetic component), which affects the insert. The Eddy currents induced inside the insert, aside being a source of heat, cause the creation of EM fields inside the metal (The Lorentz force) [2]. It's the result of an interaction of induced Eddy currents with the created magnetic field $[3 \div 5]$. These forces are responsible for two important properties of induction smelting:

- changes of the free metal surface,

- mixing of the metal in a typical form, marked on Figure 1.

Induction smelting, despite wide use, has several notable disadvantages. The use of typical crucibles could cause intense reactions of the crucible with the molten metal, present in the case of titanium or zirconium [6].

A different technology for induction smelting is eliminating partially the disadvantages of classical crucible smelting is smelting in induction furnaces with a so colled cold crucible (Fig. 2).

Simmilarly as to crucible induction furnaces, inside these aggregates appear the same phenomena during heating. The only difference comes from the way energy is transferred into the insert, coming from the use of the crucible which is made from an electrically conductive material $[7 \div 11]$. It is most often made out of copper, cooled with circulating water. Similarly

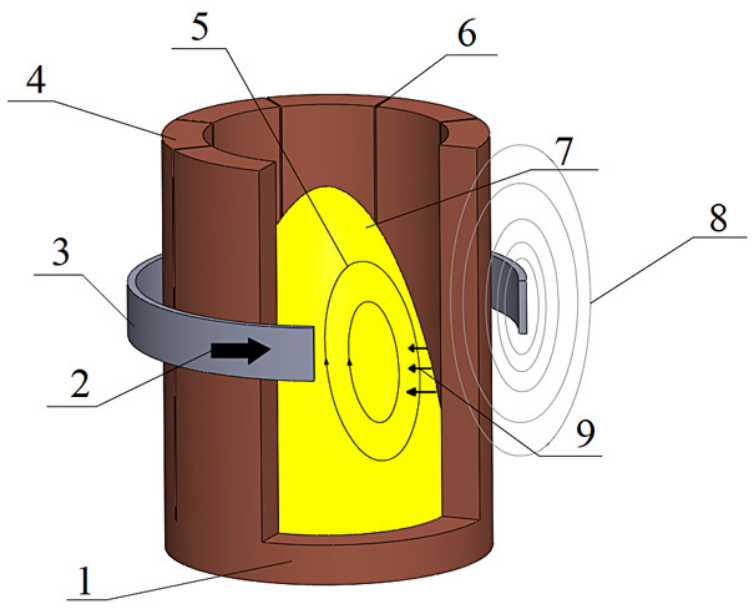

Fig. 2. Scheme of the induction furnace with a cold crucible: 1 - crucible; 2 - current; 3 - inductor; 4 - segment; 5 - melt flow; 6 - slit; 7 - meniscus; 8 - magnetic field; 9 - force density [1]

to a crucible furnace, the energy source is a copper coil. An electrically conductive crucible serves as a electromagnetic protective layer, which limits the transfer of energy from coil to insert. The solution that allows limiting of this is the division of the crucible wall into different sectors in a way, such that the flow of eddy currents induced within is as small as possible. It also allows reducing the density of currents on the outher surface of the crucible. The inner wall of the crucible induces eddy currents, which are the source of the electromagnetic field and allow for energy to exit inside the insert. The entire system, composed of the coil and selected crucible, acts as an electric transformer, its primary element being the induction coil, and secondary being the separated crucible. This solution causes that eddy currents are primarly created inside the crucible, being the source of a secondary electric field induced within the insert $[12 \div 13]$.

The purposes of this work have been accepted as:

- Creating a method for assessing the real surface area of liquid metal molten inside an induction furnace.

- Approximating the surface of liquid Al-Zn alloy melted using ICF and CCF technology.

- Conducting sample smelting of these alloys in variable pressure and working power conditions.

- Assessing the level of zinc elimination from the examined alloy during the experiments conducted. 


\section{RESEARCH METHODOLOGY}

The shape of a cold crucible is the same as a typical crucible made from fire resistant material. Inside the crucible with a massive (single piece) bottom, the magnetic field is generated primarly by the side walls. The repulsive forces induced inside the material by the secondary electromagnetic field, allow complete elimination of contact with the crucible wall. The molten material is kept inside the cooled down bottom, where a thin solid layer is created (so called "skull"), created on the intersect between the liquid metal and the "cold" crucible. Taking into account the intensity of metal mixing, the surface with contact with the bottom is very high which limits the ability of heating the insert. Inside a split crucible, the magnetic field intensifies at the top and bottom of the crucible, The same kind of electromagnetic field is induced inside the insert, causing it to levitate. The exchange of heat between the insert and crucible exists primarly due to radiation.

A disadvantage of cold crucible induction furnaces, compared to regular crucible induction furnaces, is low efficiency caused by power loss within the cold crucible (the joule effect). There exists a possibility for increasing the efficiency by using low frequency $(50 \mathrm{~Hz})$ and a sectored crucible wall (a few millimeters) made out of a thin conductive material. The crucible becomes in that case partially "transparent" for the magnetic field, which increases its electric efficiency. Chosen sectors of the crucible most often are cooled down on their own. However to fulfill the rule of optimal coil usage, an appropriate relation between the diameter of the crucible and the penetration depth of the field d/s [14]. For lower frequency, the crucible must have a larger diameter.

Phisical correlaction in induction furnaces

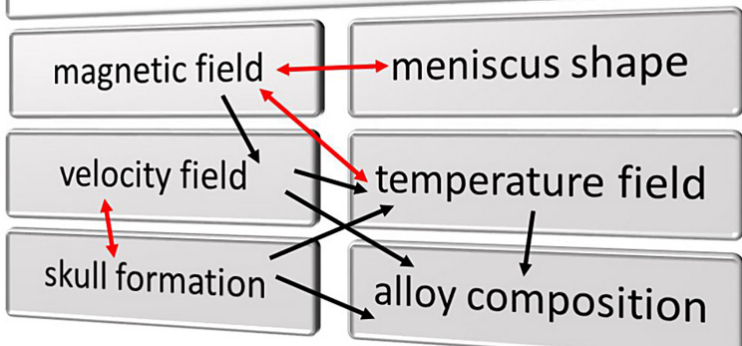

Fig. 3. Physical correlations occurring in the melting process in induction crucible furnaces [1]
This causes difficulty in finding the optimal construction regarding the frequency of the electricity flowing through the induction coils.

The complexity of physical corelations during melting inside an induction furnace was shown on Figure 3.

Increasing the free surface of the liquid metal during smelting inside induction furnaces could affect the effectiveness of heterogenic processes taking place on the liquid metal - gas phase surface. Such processes are for example: vacuum degassing of liquid metal, or evaporation of high gas pressure impurities. Mixing metal in the process of induction smelting can lead to intense transport of heat and mass, which leads to desired equality of temperature and chemical composition inside the entire alloy $[15 \div 16]$. Knowing the surface area of the metal bath allows, among other things, to conduct proper kinetic analysis of these processes. Such knowledge is required in the case of modernizing existing technologies and in creating new technology. In the case of analyzing the processes of metal and alloy refinement through their smelting inside vacuum induction furnaces, most often the phenomenon of a meniscus appearing on the metal bath surface is ignored, which can cause errors in interpreting the results. Very often it is assumed that the bath surface is similar to the cross section surface of the crucible inside of which the metal is placed. In the presented article it is discussed, how working power of vacuum induction furnaces affects the size of liquid Al-Zn alloy, and indirect losses in zinc in processes of smelting in these aggregates.

\section{EXPERIMENTAL PROCEDURES}

The research experiments were performed on a multi-component standard grade of Al-Zn alloy, its composition is presented in Table 1.

The melting furnaces applied in the experiments were the Seco-Warwick VIM-20 vacuum induction melting furnace and vacuum furnace with cold crucible ISM 2-200. The frequency was a constant parameter due to the design of the furnaces and their optimal use. This frequency was respectively $3.5 \mathrm{kHz}$ for ICF and $8 \mathrm{kHz}$ CCF $[17,18]$.

A sample of the investigated alloy $(1 \mathrm{~kg})$ was, after measuring appropriate mass, placed inside the crucible. Depending on the type of the furnace it was either the Isopress 1126-MG951 Capital 
Table 1. Chemical composition of the investigated alloy

\begin{tabular}{|c|c|c|c|c|c|c|c|c|c|}
\hline \multicolumn{10}{|c|}{ Content of basic alloy components, wt. \% } \\
\hline $\mathrm{Zn}$ & $\mathrm{Mg}$ & $\mathrm{Cu}$ & $\mathrm{Mn}$ & $\mathrm{Fe}$ & $\mathrm{Si}$ & $\mathrm{Cr}$ & $\mathrm{Ti}$ & $\mathrm{Zr}$ & $\mathrm{Al}$ \\
\hline 6.3 & 2.5 & 1.6 & 0.3 & $<0.5$ & $<0.4$ & 0.23 & $<0.05$ & 0.01 & residue \\
\hline
\end{tabular}

Refractories crucible, composed of $\mathrm{MgO}$ or a cold crucible cooled with water made of copper. On Figure 4 and 5 a) the crucibles used during the examination are shown. On Figure 4 and 5 b) the placing of the insert in relation to the induction coil during heating was shown in both furnaces.

The realization of all experiments was conducted according to the following schematic. First using a mechanical pump and a Roots pump, proper pressure was created inside the furnace chamber. Next, the power generator was turned on and the insert was melted. After reaching the agreed upon temperature the insert was kept inside for $600 \mathrm{~s}$. Temperature measurement was conducted using a thermoelectric type B sensor - PtRh30-PtRh6 and an optical pirometer. After time above has passed the molten sample was removed. Next the acquired material underwent a)

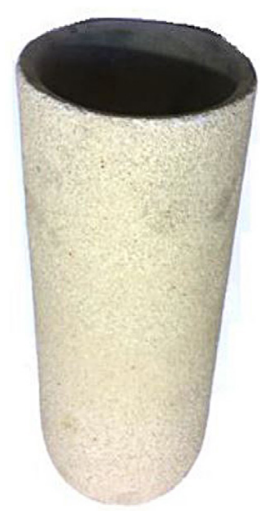

b)

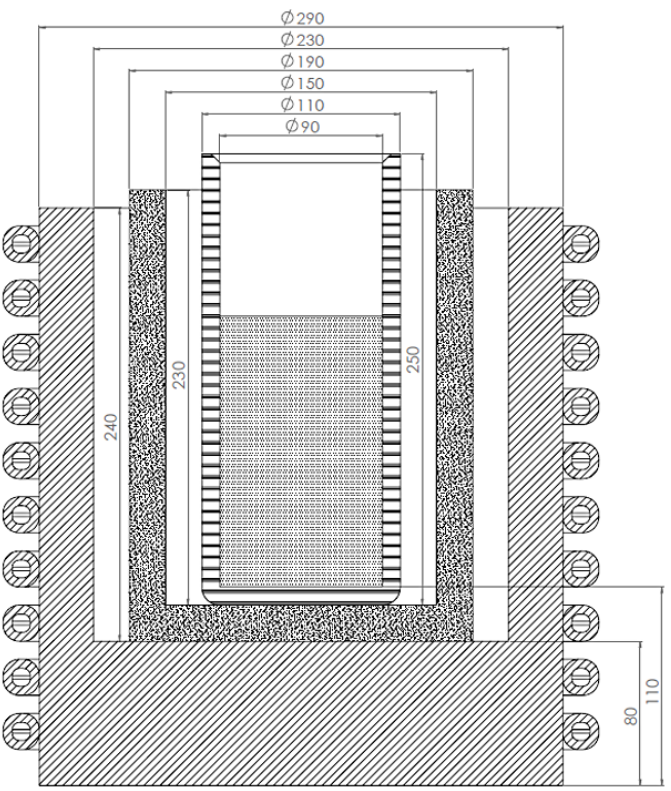

c)

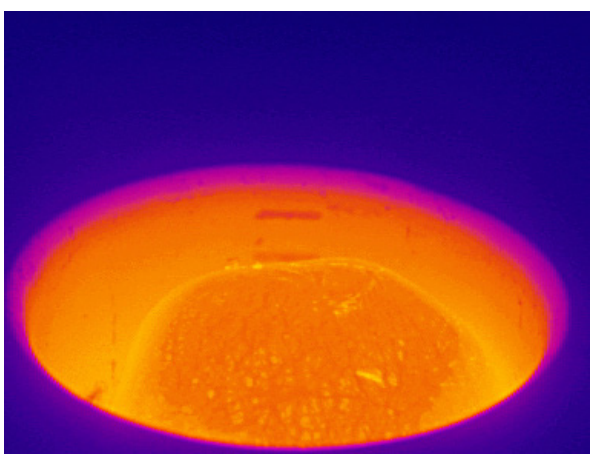

Fig. 4. ICF a) ceramic crucible, b) dimensions, c) photo of the surface of the liquid aluminum alloy fused at ICF [1]

a)

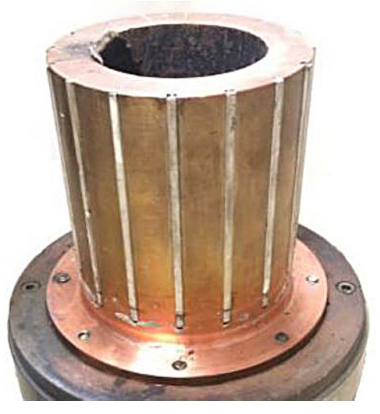

b)

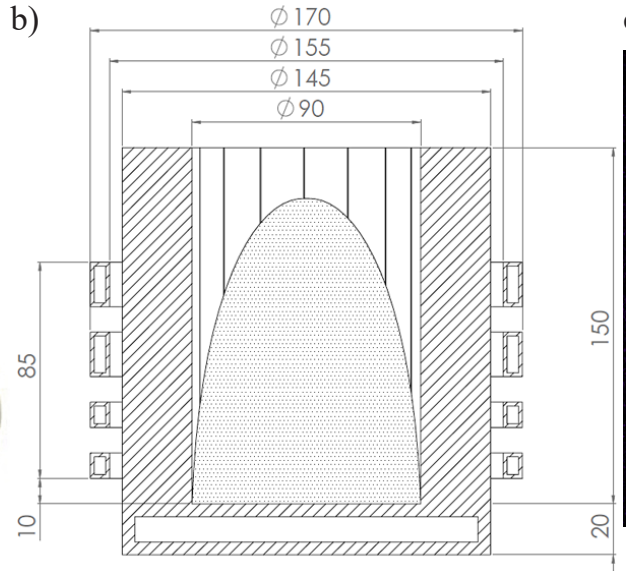

c)

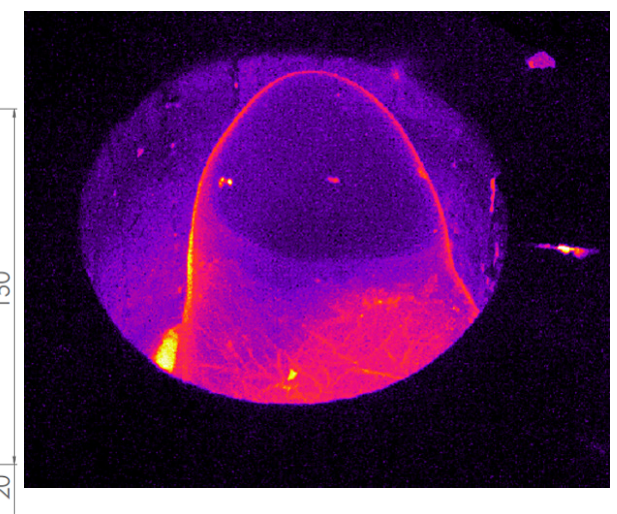

Fig. 5. CCF a) copper crucible, b) dimensions, c) photo of the surface of the liquid aluminum alloy fused at CCF [1] 
chemical examination. The analysis was conducted five times for each sample. After the experiment has finished, the liquid metal was cast into graphite molds. For chemical analysis, atomic absorption spectrometry was used with the use of the ASA Solar device.

The examination happened within a crucible furnace in the temperature range of 953-1103 K. For the furnace with a cold crucible the experiments were carried out in the temperature of $953 \mathrm{~K}$. In the case of the crucible furnace, the working power was within the $8-22 \mathrm{~kW}$ range, for the furnace with the cold crucible, the working power was within $70-130 \mathrm{~kW}$. Working pressure in both aggregates changed between 10 to $1000 \mathrm{~Pa}$.

\section{EXPERIMENTAL RESULTS AND DISCUSSION}

\section{Determination of the surface of a liquid alloy}

As stated previously, during the process of casting metal or alloys within induction furnaces, the phenomenon of meniscus creation is present, Its shown on Figure 4 and 5 on which is an example photo of the surface of the examined aluminum alloy melted within a CCF and ICF.

To estimate the size of the surface a method of determining the area consisting of four stages was proposed $[19 \div 22]$ :

- taking pictures of the molten metal with the use of a high-speed camera,

- determination of the resulting meniscus geometry on the basis of the obtained photos,

- determination of the functions of the curves describing the meniscus for various process parameters,

- estimation surface area using the program Wolfram Mathematica $\left(\mathrm{S}_{1}\right)$.

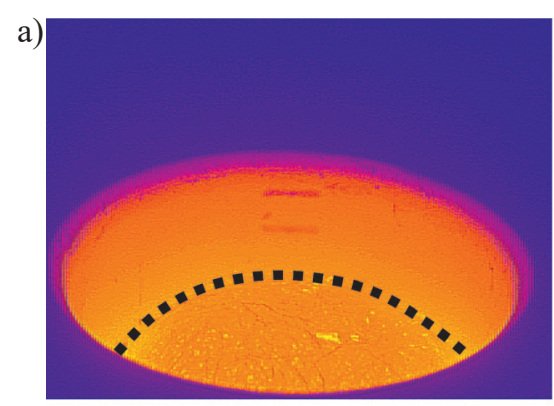

$17 \mathrm{~kW}$

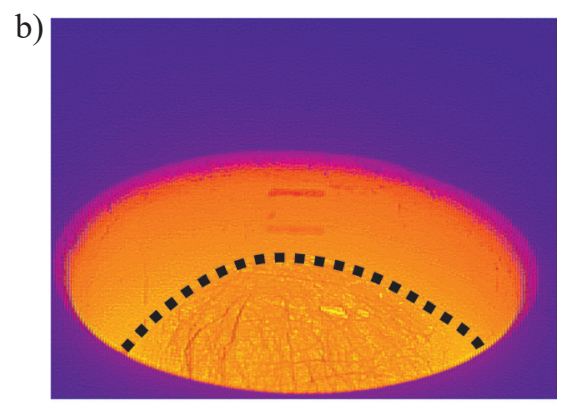

$22 \mathrm{~kW}$

Fig. 6. Images of the surface of aluminium melted using various operating power values (ICF): a) $17 \mathrm{~kW}$; b. $22 \mathrm{~kW} \mathrm{[1]}$

As part of the first stage, using PSC PI 1M camera and the FLIR thermal imaging camera a series of photos of the liquid metal was taken during the melting process for the assumed operating parameters of the furnace [23]. The use of the WebPlotDigitizer 4.1 program allowed to place points on the photos describing the resulting geometry. On this basis, a line and a function describing the shape of the interface were determined. Figure 6 shows an exemplary photo of a liquid alloy meniscus with marked points.

Table 2 shows meniscus field values estimated for each experiment using both proposed calculation methods. The value of DS

Table 2. Results of the meniscus surface area of liquid alloys estimated with the use of the proposed calculation methods

\begin{tabular}{|c|c|c|c|c|c|}
\hline No. & $P, \mathrm{~kW}$ & Furnace & $S_{1}, \mathrm{~cm}^{2}$ & $S_{2}, \mathrm{~cm}^{2}$ & $h_{v^{\prime}} \mathrm{cm}$ \\
\hline 1 & 8 & ICF & 88.1 & 86.3 & 4.3 \\
\hline 2 & 12 & ICF & 92.4 & 85.0 & 5 \\
\hline 3 & 17 & ICF & 108.7 & 99.8 & 7 \\
\hline 4 & 22 & ICF & 155.0 & 155.0 & 10 \\
\hline 7 & 70 & CCF & 280.0 & 265.6 & 13 \\
\hline 8 & 100 & CCF & 311.8 & 313.4 & 14 \\
\hline 9 & 130 & CCF & 330.3 & 329.8 & 15 \\
\hline
\end{tabular}

$S 1$ - area estimated with the use of Wolfram Mathematica software.

$S 2$ - area estimated with the use of MicroStation software. 
a)

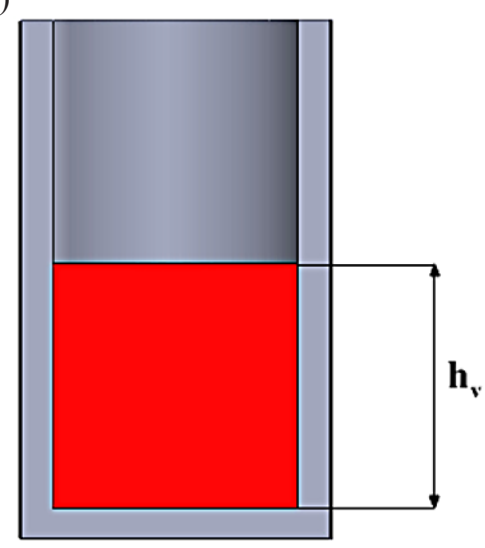

b)

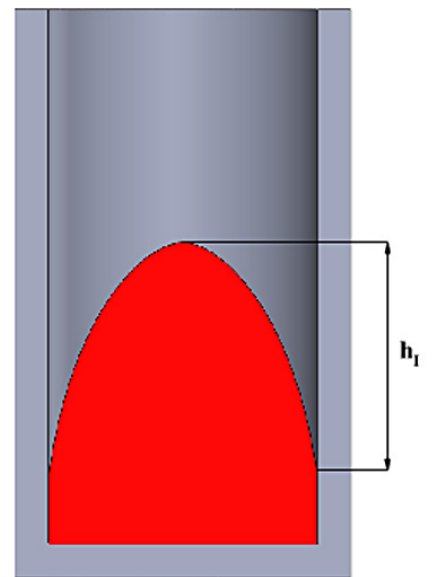

Fig. 7. The method of determining the height of the meniscus a) ICF $\left.\left(h_{v}\right), b\right) \operatorname{CCF}\left(h_{I}\right)[1]$

The difference between the Surface $S_{1}$ i $S_{2}$. For the crucible induction furnace $h_{\mathrm{v}}$ is the meniscus height measured from the surface of liquid metal in contact with the crucible wall to the meniscus top (Fig. 7a). In the case of the cold crucible induction furnace, the height marked as $h_{I}$ (Fig. 7b). Was measured from the bottom of the crucible to the tip of the meniscus. This comes from the shape of the created meniscus. In furnaces with a cold crucible, the metal has an oval shape and there is no contact with the side surface of the crucible and only partially with the bottom of the crucible.

To estimate the surface area of the meniscus, it is necessary to know the function describing the shape of the surface of the liquid aluminum.
For this purpose the Wolfram Mathematica program was used. The surface area of the resulting figure was determined by the curve's rotation around the $\mathrm{X}$ axis.

On Figure 8 example meniscus shapes were compiled, created using the Wolfram Mathematic program for the aluminum alloy (70 and $130 \mathrm{~kW}$ ) molten inside a cold crucible furnace

According to the data shown in Table 2, it can be ascertained that in the case of melting alloy inside a crucible furnace, power increase from 8 to $22 \mathrm{~kW}$ causes the increase of liquid alloy surface from 88.1 to $155 \mathrm{~cm}^{2}$ In the case of a cold crucible furnace, the increase of power from 70 to $130 \mathrm{~kW}$ causes the increase of liquid alloy surface from 280 to $330.3 \mathrm{~cm}^{2}$.

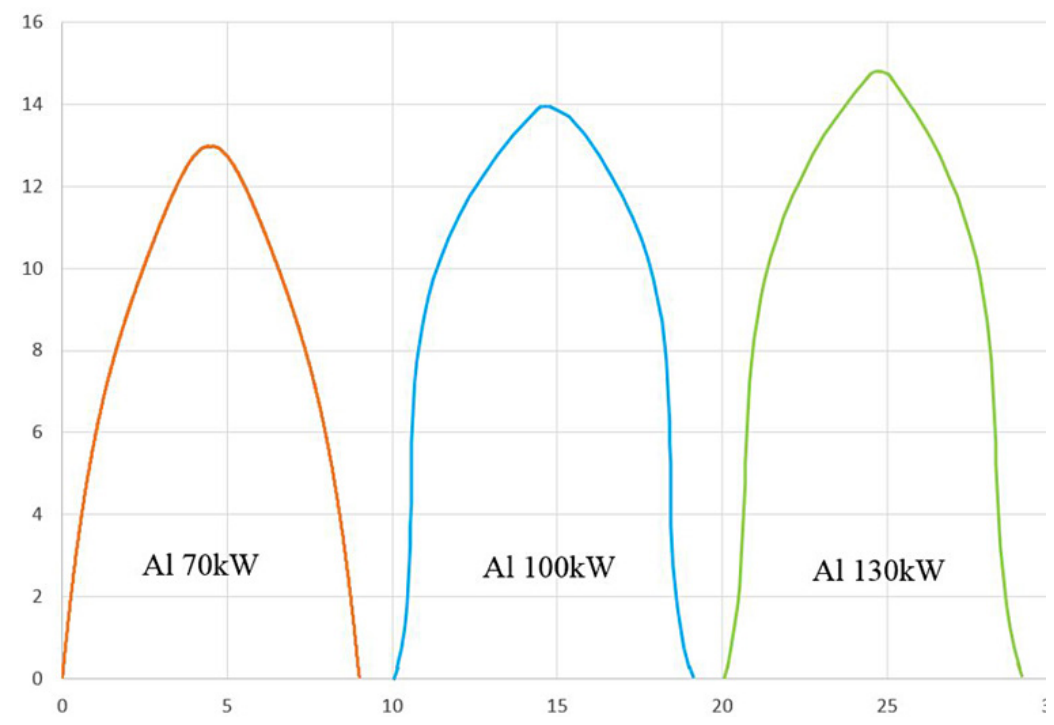

Fig. 8. Aluminum alloy meniscus shapes obtained from the Wolfram Mathematica program for CCF $P=70 \mathrm{~kW}, 100 \mathrm{~kW}$ and $130 \mathrm{~kW}$ (X-axis indicates the height of the meniscus in $\mathrm{cm}$, for the Y-axis diameter of the crucible in $\mathrm{cm}$ ) [1] 


\section{Determination of the influence of the}

furnace operating power on zinc losses in the smelting process of the tested $\mathrm{Al}-\mathrm{Zn}$ alloy

Increasing the free Surface of molten alloy during casting inside induction furnaces can strongly impact the effectivity of heterogenic processes happening on the surface. Such processes are for example vacuum degassing of liquid metal, or evaporation of high vapor pressure alloy ingredients. During casting of the examined Al.-Zn alloys, zinc loss was analyzed caused from evaporation being the effect of large balance pressure differences between aluminum and zinc.

In Table 3 and 4 compiled together were calculated mass and density losses of zinc from the examined alloy during melting in the induction furnaces used. On Figure 9 and 10 summarized graphical interpretation of these results.

Based on the analysis of the results, It can be stated that for smaller power furnaces (12 and 70 $\mathrm{kW}$ respectively) the zinc loss inside the alloy is larger than in the case of a cold crucible furnace. The zinc mass loss from the cold crucible for pressure of $10 \mathrm{~Pa}$ was $40 \mathrm{~g}$, for pressure of $1000 \mathrm{~Pa}$ was $12 \mathrm{~g}$. For the crucible furnace, these values resulted in $38 \mathrm{~g}$ and $8 \mathrm{~g}$ respectively. Checked however, was that together with the power increase, this trend reverses. For furnace power respectively 22 and $130 \mathrm{~kW}$, zinc mass loss for the cold crucible furnace at $10 \mathrm{~Pa}$ was $50.68 \mathrm{~g}$, for pressure at $1000 \mathrm{~Pa}$ was $28.5 \mathrm{~g}$ for a crucible furnace $60.69 \mathrm{~g}$

Table 3. Summary of aggregate mass loss of zinc and zinc average flux density (ICF)

\begin{tabular}{|c|c|c|c|c|c|}
\hline$T, \mathrm{~K}$ & $P, \mathrm{~kW}$ & $p, \mathrm{~Pa}$ & $\Delta m, \mathrm{~g}$ & $\Delta m, \%$ & $N, \mathrm{~g} /\left(\mathrm{cm}^{2} \cdot \mathrm{s}\right)$ \\
\hline \multirow{4}{*}{953} & \multirow{4}{*}{8} & 1000 & 4.14 & 6.58 & $7.84 \cdot 10^{-05}$ \\
\hline & & 500 & 9.84 & 15.67 & $1.86 \cdot 10^{-04}$ \\
\hline & & 100 & 13.63 & 21.66 & $2.58 \cdot 10^{-04}$ \\
\hline & & 10 & 32.48 & 51.50 & $6.14 \cdot 10^{-04}$ \\
\hline \multirow{4}{*}{1013} & \multirow{4}{*}{12} & 1000 & 8.83 & 14.04 & $1.59 \cdot 10^{-04}$ \\
\hline & & 500 & 11.76 & 18.68 & $2.12 \cdot 10^{-04}$ \\
\hline & & 100 & 19.16 & 30.54 & $3.46 \cdot 10^{-04}$ \\
\hline & & 10 & 38.58 & 61.30 & $6.96 \cdot 10^{-04}$ \\
\hline \multirow{4}{*}{1073} & \multirow{4}{*}{17} & 1000 & 26.95 & 42.73 & $4.13 \cdot 10^{-04}$ \\
\hline & & 500 & 31.18 & 49.50 & $4.78 \cdot 10^{-04}$ \\
\hline & & 100 & 38.58 & 61.11 & $5.92 \cdot 10^{-04}$ \\
\hline & & 10 & 41.93 & 66.36 & $6.43 \cdot 10^{-04}$ \\
\hline \multirow{4}{*}{1103} & \multirow{4}{*}{22} & 1000 & 49.04 & 78.15 & $5.27 \cdot 10^{-04}$ \\
\hline & & 500 & 51.38 & 81.48 & $5.53 \cdot 10^{-04}$ \\
\hline & & 100 & 54.73 & 86.61 & $5.88 \cdot 10^{-04}$ \\
\hline & & 10 & 60.69 & 96.33 & $6.53 \cdot 10^{-04}$ \\
\hline
\end{tabular}

Table 4. Summary of aggregate mass loss of zinc and zinc average flux density (CCF)

\begin{tabular}{|c|c|c|c|c|c|}
\hline$T, \mathrm{~K}$ & $P, \mathrm{~kW}$ & $p, \mathrm{~Pa}$ & $\Delta m, \mathrm{~g}$ & $\Delta m, \%$ & $N, \mathrm{~g} /\left(\mathrm{cm}^{2} \cdot \mathrm{s}\right)$ \\
\hline \multirow{4}{*}{953} & \multirow{4}{*}{70} & 1000 & 12.37 & 19.64 & $7.37 \cdot 10^{-05}$ \\
\hline & & 500 & 14.87 & 23.60 & $8.85 \cdot 10^{-05}$ \\
\hline & & 100 & 21.27 & 33.76 & $1.27 \cdot 10^{-04}$ \\
\hline & & 10 & 40.19 & 63.86 & $2.39 \cdot 10^{-04}$ \\
\hline \multirow{4}{*}{953} & \multirow{4}{*}{100} & 1000 & 26.16 & 41.57 & $1.40 \cdot 10^{-04}$ \\
\hline & & 500 & 28.87 & 45.86 & $1.54 \cdot 10^{-04}$ \\
\hline & & 100 & 33.99 & 53.46 & $1.82 \cdot 10^{-04}$ \\
\hline & & 10 & 49.33 & 77.69 & $2.64 \cdot 10^{-04}$ \\
\hline \multirow{4}{*}{953} & \multirow{4}{*}{130} & 1000 & 28.50 & 45.10 & $1.44 \cdot 10^{-04}$ \\
\hline & & 500 & 31.93 & 50.48 & $1.61 \cdot 10^{-04}$ \\
\hline & & 100 & 36.23 & 57.00 & $1.83 \cdot 10^{-04}$ \\
\hline & & 10 & 50.78 & 80.29 & $2.56 \cdot 10^{-04}$ \\
\hline
\end{tabular}




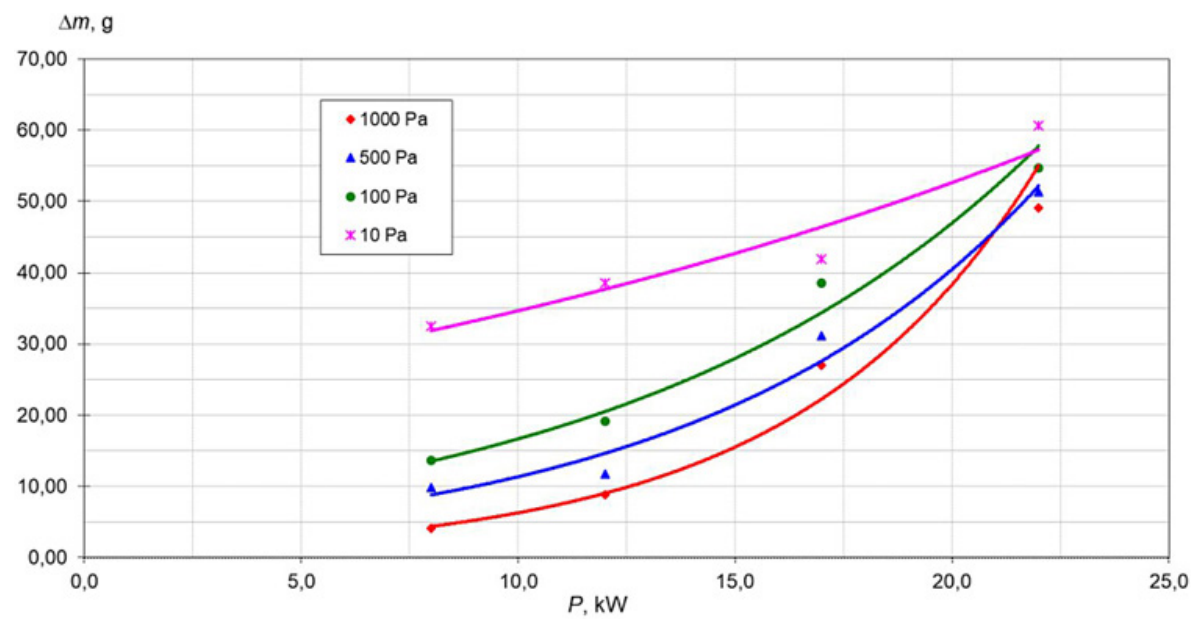

Fig. 9. Dependencies of zinc weight loss from an alloy as a function of ICF operating power [1]

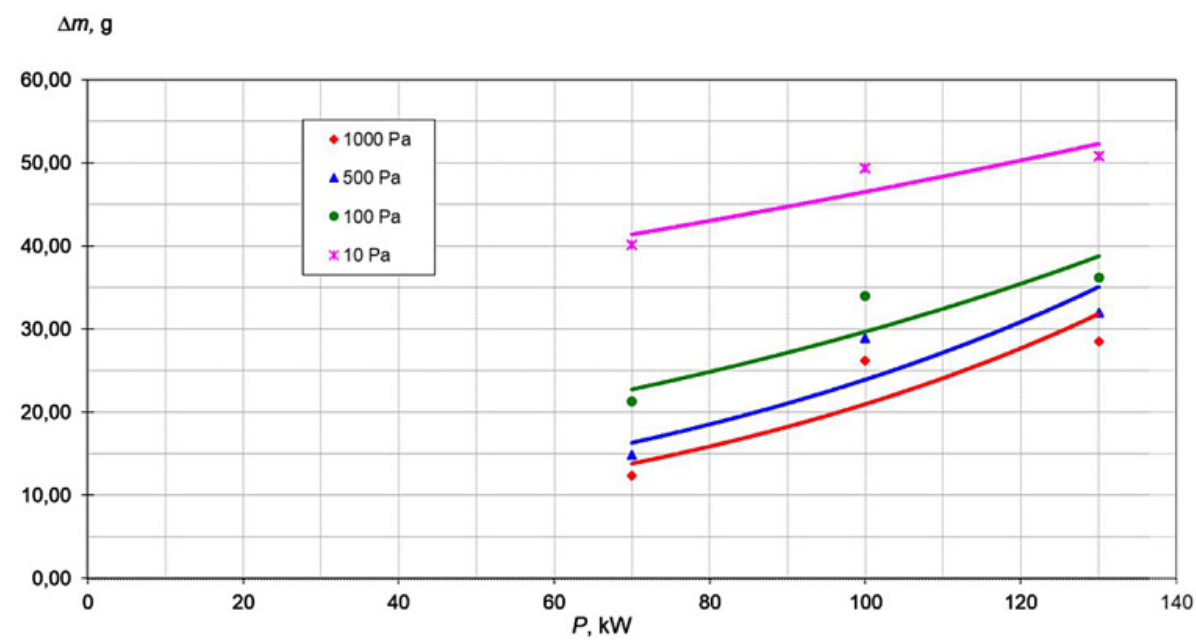

Fig. 10. Dependencies of zinc weight loss from an alloy as a function of CCF operating power [1]

and $49.04 \mathrm{~g}$ respectively. This comes from the fact, that for lower power furnaces the interphase surface is much larger for the cold crucible furnace. For higher power a notable increase in liquid metal area can be observed for crucible furnaces (around two times), for cold crucible furnaces the increase is only about $20 \%$. It has to be remembered, that despite the interphase surface area is larger for the cold crucible furnace, increased metal mixing can also cause faster evaporation [24, 25]. It is more intense for crucible furnaces, the power values of both furnaces have been chosen so that, while taking into account both device efficiency averages, created power was similar.

\section{CONCLUSIONS}

Based on the conducted experiments and analysis the following can be concluded:
1. During melting the examined aluminum alloy inside a crucible induction furnace and a cold crucible induction furnace, a large distance in metal liquid bathing can be observed. The chosen surface area of the created meniscus during alloy melting are much larger for the cold crucible furnace than for the crucible furnace.

2. Increasing working power of the aggregates use cause an increase in bathing area. For example, for an alloy melted inside an induction crucible furnace, the increase in power from 12 to $22 \mathrm{~kW}$ causes a bathing surface change from 92 to $155 \mathrm{~cm}^{2}$. For a cold crucible furnace, power increase from 70 to $130 \mathrm{~kW}$ caused bathing surface increase from 280 to $330 \mathrm{~cm}^{2}$.

3 . The zinc elimination process from the aluminum alloy is more intense when using a melting aggregate of a cold crucible furnace. For example at a temperature of $953 \mathrm{~K}$ for Al-Zn alloys, zinc. 
4. Increase of working power of both aggregates causes increase in zinc removal from the bath.

\section{Acknowledgements}

This study is part of the 11/040/BK_21/0023 funded by Silesian University of Technology.

\section{REFERENCES}

1. Wecki B. Analysis of the influence of the contact area size between the liquid metal phase and the gas phase on the efficiency of the metal refining process in induction crucible furnaces. PhD Dissertation Gliwice 2018.

2. Deng H., Dong J., Boi F., Saunders T., Hu C., Grasso S. 2020. Magnetic Field Generated during Electric Current - Assisted Sintering: From Health and Safety Issues to Lorentz Force Effects. Metals. 10: 1653.

3. Smalcerz A., Przylucki R. 2013. Electromagnetic field analysis of inductor - robot-workpiece system. Metalurgija. 52: 223-226.

4. Niklewicz M., Smalcerz A. 2010. Application of three-coil cylindrical inductor in induction heating of gears. Electrical Review. 86: 333-335.

5. Niklewicz M., Smalcerz A. 2008. Estimation of system geometry and inductor frequency importance in induction hardening process of gears. Electrical Review. 84: 219-224.

6. Biesuz M., Saunders T., Ke D., Reece J.M., Hu C., Grasso S. 2021. A review of electromagnetic processing of materials (EPM): Heating, sintering, joining and forming. Journal of Materials Science \& Technology. 69: 239-2722020.

7. Gombert D., Richardson J., Aloy A., Delbert D. 2002. Cold-crucible design parameters for next generation HLW melters. WM'02 Conference Tucson.

8. Vogt M., Bernier F., Mühlbauer A., Blum M., Jarczyk, G. 2000. Experimental investigation of temperature field and energy flows in induction furnace with cold crucible and a practical application of the results. Proc. Int. Conf. Electromagnetic Processing of Materials EPM 2000 Japan.

9. Baake E., Nacke B., Bernier F., Vogt M., Mühlbauer A., Blum, M. 2001. Experimental and numerical investigations of the temperature field and melt flow in the induction furnace with cold crucible. Proc. Int. Sem. on Heating by Internal Sources HIS.

10. Lavers J.D. et al. 1973. Current distribution, forces and circulation in the coreless furnace, IEEE Transactions on Industry Applications. 1(9).

11. Bojarevics V., Djambazov G., Harding R., Pericleous K., Wickins M. 2002. Investigation of the cold crucible melting, Process: Experimental and Numerical Study, Proc. Fifth Int. pamir Conf. on Fundamental and Applied MHD. 2 II - 77.
12. Delage D., Ernst R., Driole J. 1982. Induction melting in a cold crucible, Proc. Symp. IUTAM, Cambridge. 108.

13. Gagnoud A., Etay J., Garnier M. 1988. The levitation melting process using cold crucible technique. ISIJ international. 28: 38.

14. Umbrashko A., Baake E., Nacke B., Kirpo M., Jakovics A. 2005. Improvement of the cold crucible melting process using LES modelling, Proc. 15th Riga and $6^{\text {th }}$ Int. Conf. on Fundamental and Applied MHD.

15. Szala M., Beer-Lech K., Gancarczyk K., Kilic O.B., Pedrak P., Ozer A., Skic A. Microstructural characterization of Co-Cr-Mo casting dental alloys. Advances in Science and Technology - Research Journal. 2017, 11. 76-82.

16. Naprstkova N., Kraus P., Cais J., Stancekova D., Miturska I. 2018. Analyses of calcium influence on the AlSi9CuMnNi alloy. Advances in Science and Technology - Research Journal. 12: 32-38.

17. Smalcerz A. Oleksiak B., Siwiec G. 2015. The influence crucible arrangement on the electrical efficiency of the cold crucible induction furnace. Archives of Metallurgy and Materials. 60.

18. Golak S., Przyłucki R., Smołka J., Buliński P., Ciepliński P. 2018. Influence of a cold crucible geometry parameters on electrical efficiency. International Journal of Applied Electromagnetics and Mechanics. 56: 165-172.

19. Schieber D. 1986. Electromagnetic induction phenomena. Springer. Berlin.

20. Song J.H., Min B.T., Kim J. H. Kim H.W. Hong S.W., Chung S.H. 2005. An electromagnetic and thermal analysis of a cold crucible melting, International Communications in Heat and Mass Transfer. 32: 1325-1336.

21. Gou J., Liu Y., Su Y., Ding H., Liu G., Jia J. 2000. Evaporation behaviour of aluminum during the cold crucible induction skull melting of titanium aluminum alloys. Metallurgical and Materials Transactions B. 31B: 837-844.

22. Spitans S., Jakovics A., Baake E., Nacke B. 2011. Numerical modelling of free surface dynamics of melt in an alternate electromagnetic field, Magnetohydrodynamics. 47: 385-397.

23. Urzedowski A., Wojcicka-Migasiuk D.,Buraczynska B. 2020. Visual Effects of Surface Emissivity in Thermal Imaging. Advances in Science and Technology - Research Journal. 14. 215-222.

24. Golak S., Przylucki R., Barglik J. 2014. Determination of a mass transfer area during metal melting in a vacuum induction furnace. Archives of Metallurgy and Materials. 59: 287-292.

25. Jinjie G., Jun J., Yuan S.L., Guizhong L., Yanqing S., Hongsheng D. 2000. Evaporation behavior of aluminum during the cold crucible induction skull melting of titanium aluminum alloys. Metallurgical and Materials Transactions B. 31B: 837-844. 